\title{
A dimensão visual no livro didático de língua inglesa
}

\section{Daiane Aline Kummer,}

\author{
Universidade Federal de Santa Maria
}

\begin{abstract}
Resumo
O objetivo deste estudo é verificar como atividades de leitura de um livro didático consideram a dimensão visual dos gêneros. A análise adota uma perspectiva multimodal associada à Análise Crítica de Gênero. De 19 atividades, 16 focam na metafunção representacional, três na interativa e nenhuma atividade na composicional.

Palavras-chave: livro didático de língua inglesa, dimensão visual, multiletramento.
\end{abstract}

\begin{abstract}
The objective of this study is to verify how the reading activities of a textbook deal with the visual dimension of genres. The analysis follows a multimodal perspective associated with Critical Genre Analysis. Of the 19 activities, 16 focus on the representational metafunction, three on the interactive and none on the compositional.
\end{abstract}

Key-words: English language textbook, visual dimension, multiliteracy.

\section{INTRODUÇÃO}

Visto a grande variedade de elementos visuais que compõem os gêneros discursivos multimodais (KRESS; van LEEUWEN, 2006), percebe-se a necessidade de se desenvolver habilidades que considerem tais elementos visuais o fim de uma participação bem sucedida nos diversos gêneros. Uma leitura que considere tanto linguagem verbal, como linguagem não verbal está relacionada à questão do multiletramento, o qual, segundo Cope e Kalantzis (2000), contempla, dentre outros aspectos, a capacidade de agir socialmente por meio dos diferentes modos de representação nos variados contextos nos quais interagimos. Em vista disso, uma vez que educadores e alunos compreendem os diferentes modos de significado empregados nos textos, assim como, as diversas diferenças linguísticas, eles são capazes de "ver a si mesmos como participantes ativos nas mudanças sociais" (COPE; KALANTZIS, 2000, p. 7).

No contexto de ensino de línguas, um gênero discursivo multimodal que faz parte 
da rotina das escolas é o livro didático (TICKS, 2003) e, sendo assim, é um dos recursos por meio do qual o professor pode promover o multiletramento dos alunos. Aliado a isso está a inclusão do componente curricular de língua estrangeira no ensino médio, que tornou obrigatória a seleção de um livro didático de língua estrangeira em tal nível (BRASIL, 2011a, p. 7). Portanto, o foco deste estudo ${ }^{1}$ é um livro de uma coleção de livros didáticos de língua inglesa (LDI), Prime (DIAS; JUCÁ; FARIA, 2010).

Além disso, tendo em vista que são poucos os estudos que analisam o LDI sob a ótica da análise do discurso multimodal (ver, como exceção, GRAY, 2011), há uma lacuna no conhecimento sobre como a dimensão visual dos gêneros discursivos apresentados no LDI são explorados nesses materiais. Nesse sentido, o objetivo deste trabalho é verificar como as atividades de leitura propostas no LDI Prime (DIAS; JUCÁ; FARIA, 2010) consideram a dimensão visual dos gêneros apresentados, utilizando como ferramenta a Gramática do Design Visual (KRESS; van LEEUWEN, 2006).

\section{ABORDAGENS TEÓRICAS}

A análise do discurso multimodal (KRESS; van LEEUWEN, 1996/2006), aliada aos princípios da Análise Crítica de Gênero (MOTTA-ROTH; 2008) servem de base teórica e metodológica para este trabalho. Segundo Motta-Roth (2008, p. 353), a Análise Crítica de Gênero amplia o "foco dos estudos de gênero da léxico-gramática para o discurso [o que] indica a busca por um entendimento mais rico da conexão entre texto e contexto". Parte-se do pressuposto de que "o conhecimento humano é construído através de gêneros - linguagem usada em contextos recorrentes da experiência humana socialmente compartilhados" (MOTTA-ROTH, 2006, p. 147). Dessa forma, a organização retórica dos gêneros discursivos é reconhecida e determinada pelos objetivos comunicativos de seus participantes (SWALES, 1990; 2006).

Na sua materialidade linguística, cada gênero resulta da fusão de três metafunções (HALLIDAY; HASAN, 1989): ideacional, interpessoal e textual. Considerando essa multifuncionalidade da linguagem, Kress e van Leeuwen (1996; 2006) abordam os elementos visuais dos textos multimodais, ou seja, a linguagem não verbal, e propõem

\footnotetext{
${ }^{1}$ Este estudo é parte integrante do trabalho final de Especialização em Linguagem e Representação, orientado pela professora Graciela Rabuske Hendges, realizado no ano de 2012.
} 
que esta também realiza três metafunções, chamadas por eles de representacional, interativa e composicional (respectivamente condizentes com as metafunções propostas por Halliday e Hasan (1989)). A metafunção representacional corresponde à representação de "participantes e a sua relação" com o mundo (KRESS; van LEEUWEN, 2006, p. 42). A metafunção interativa apresenta "uma relação social particular entre o produtor, o leitor, e o objeto representado", como explicam Kress e van Leeuwen (2006, p. 42). Já a metafunção composicional é responsável pela explicação dos significados produzidos pela organização do texto visual (Ibid, p. 43).

A Gramática do Design Visual, proposta por Kress e van Leeuwen (2006), é uma possibilidade de entender as imagens não apenas a partir de seu valor artístico, mas também pelas suas dimensões sociais, políticas e comunicativas (Ibid). Os autores consideram os textos multimodais como construídos por diferentes modos semióticos (p. 20), e o conjunto de categorias linguísticas proposto na Gramática do Design Visual (Ibid) permite uma análise sistematizada dos significados realizados por essas semioses. Nesse sentido, intenta-se verificar, a partir dessa análise, a maneira como o aluno pode desenvolver um conhecimento que o possibilite ler as semioses visuais dos gêneros multimodais e, assim, participar das diferentes práticas sociais, ou seja, que ele seja letrado nessas.

Cope e Kalantzis (2000) propõem a noção de multiletramento, o qual dá conta de duas questões: "a multiplicidade de canais e meios de comunicação [...] e a crescente saliência da diversidade cultural e linguística” (p. 5). Segundo os autores (COPE; KALANTZIS, 2000, p.5), "uma pedagogia de multiletramentos foca em modos de representação mais amplos que a língua escrita sozinha", essa noção propõe que a língua escrita junto com os outros modos de significar são "recursos representacionais dinâmicos, que constantemente são reinventados por seus usuários a fim de atingir seus vários objetivos culturais" (Ibid).

Posto isto, é importante estar ciente de que a crescente mudança em termos da presença de elementos visuais em diferentes práticas sociais (conhecidas e novas), de que falam Cope e Kalantzis (2000), Kress e van Leeuwen (2006) e Unsworth (2001), também afeta os LDI (GRAY, 2010, p. 55). Segundo Martins (2006, p. 127) “o texto do livro didático é organizado a partir de uma diversidade de linguagens, a saber, verbal (texto escrito), 
matemática (equações, gráficos, notações), imagética (desenhos, fotografias, mapas, diagramas)", demandando habilidades para compreender esses textos. Cabe perguntar: o LDI dá conta das imagens de maneira crítica, assistindo o professor em um ensino voltado para o multiletramento?

Portanto, uma vez que o LD se caracteriza "muito mais por uma incompletude e por uma heterogeneidade de saberes, de crenças e de valores sobre a língua e seu ensino/aprendizagem do que num saber-fazer homogêneo e sem conflitos" (BUNZEN, 2005, p. 558), é de extrema relevância que tal gênero seja analisado e discutido, a fim de um manuseio mais crítico e consciente por parte dos professores.

\section{METODOLOGIA}

O corpus do presente trabalho é composto por 12 seções de leitura de um LD da coleção Prime (DIAS; JUCÁ; FARIA, 2010). Tal coleção é uma das sete coleções de língua inglesa oferecidas pelo Programa Nacional do Livro Didático (PNLD) para o ensino médio e é a melhor classificada dentre essas sete (BRASIL, 2011a).

A coleção Prime possui três volumes dos quais apenas o volume dedicado ao primeiro ano do ensino médio é analisado. Esse livro é constituído de 210 páginas e 12 unidades, subdivididas em 14 subseções, das quais a seção de leitura, "Reading beyond the words", foi selecionada para análise.

Duas etapas foram seguidas para a realização da análise: 1) análise contextual, com objetivo de buscar informações extras sobre o LDI analisado; 2) análise textual, a qual seguiu dois passos: a) mapeamento das atividades de leitura quanto a referências às imagens presentes nos textos; b) classificação das atividades em relação à metafunção explorada - Representacional, Interativa ou Composicional (KRESS; van LEEUWEN, 2006).

\section{RESULTADOS E DISCUSSÃO}

A partir do mapeamento de atividades de leitura que se referem às imagens, foi possível observar que, das 12 seções de leitura presentes no LDI Prime, em apenas seis $(4,5,9,10,11,12)$ 
há referência às imagens, ou seja, em 50\% das seções de leitura. Essas seis seções foram, então, selecionadas para análise. Do total de 58 (100\%) atividades de leitura, das seis seções analisadas, apenas 19 (32,7\%) fazem referência às imagens. Com base nesse resultado, nota-se uma carência de atividades que consideram os recursos visuais dos gêneros, apesar de alguns critérios do PNLD (BRASIL, 2011b) e mesmo do "guia do professor" do livro Prime salientarem a importância da linguagem não verbal nos textos (DIAS; JUCÁ; FARIA, 2010).

Realizada a análise das 19 atividades com base na Gramática do Design Visual (KRESS; van LEEUWEN, 2006), constatou-se que 16 atividades focam na metafunção representacional, três na metafunção interativa e nenhuma atividade tem como foco a metafunção composicional, como pode ser observado na Tabela 1.

Tabela 1.

\begin{tabular}{|c|c|c|c|}
\hline \multirow{2}{*}{ Seções/Atividades } & \multicolumn{3}{|c|}{ Metafunções } \\
\hline & $\begin{array}{l}\text { Representaci } \\
\text { onal }\end{array}$ & $\begin{array}{l}\text { Interativ } \\
a\end{array}$ & $\begin{array}{l}\text { Composicio } \\
\text { nal }\end{array}$ \\
\hline Seção 4/ 6 atividades & 4 & 2 & 0 \\
\hline Seção 5/ 1 atividade & 1 & 0 & 0 \\
\hline Seção 9/ 4 atividades & 4 & 0 & 0 \\
\hline Seção 10/ 3 atividades & 3 & 0 & 0 \\
\hline Seção 11/ 1 atividade & 1 & 0 & 0 \\
\hline Seção 12/ 4 atividades & 3 & 1 & 0 \\
\hline $\begin{array}{c}\text { Total de atividades }= \\
19\end{array}$ & $16(84,2 \%)$ & $\begin{array}{r}3 \\
(15,8 \%)\end{array}$ & 0 \\
\hline
\end{tabular}

Tabela 1. Total de atividades que fazem referência às imagens classificadas de acordo com as metafunções (KRESS; van LEEUWEN, 2006)

Para exemplificar a análise, a seção 4 do livro analisado é considerada. As atividades apresentadas nessa seção referem-se a um diagrama (Figura 1), o qual trata do assunto "múltiplas inteligências". O diagrama apresenta uma circunferência, centralizada e delimitada por oito tipos de inteligências em suas margens, quantificadas de acordo com as respostas a um questionário. Esse diagrama constrói significados representacionais, é uma representação conceitual. As representações conceituais, segundo Kress e van Leeuwen (2006, p. 79) retratam participantes "em termos de classe, ou estrutura ou significado". Dessa maneira, as diferentes múltiplas inteligências (Participantes) são classificadas em "tipos de” múltiplas inteligências, cada uma delas 
identificada por uma cor (KRESS; van LEEUWEN, 2006).

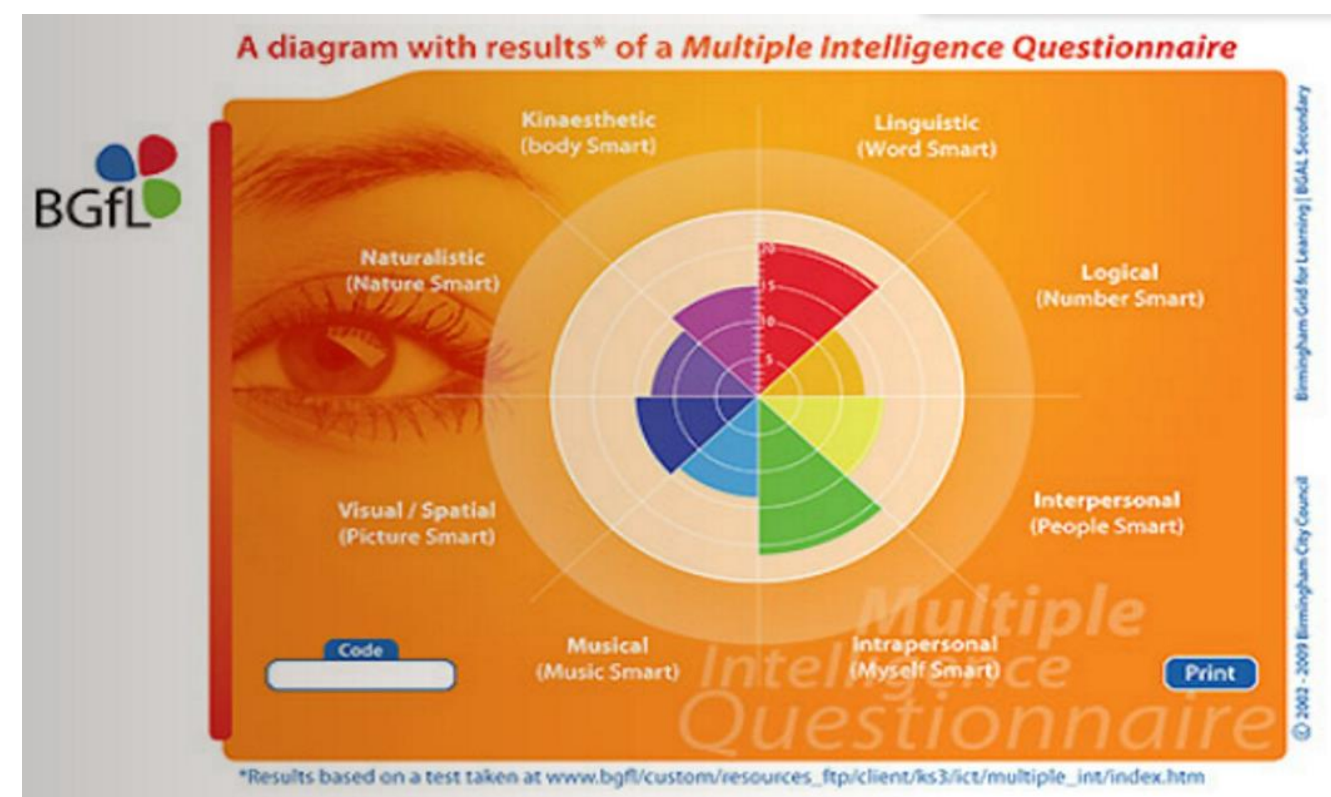

Figura 1. Diagrama da seção "Reading beyond the words" da Unidade 4

Na seção 4, seis atividades fazem referência à imagem: - 1. "[s]obre o que é o diagrama"; 2. "[o] que ele (o diagrama) mostra"; 3. "[o] que as cores e números indicam?”; 4.“[q]ual é a inteligência mais forte da pessoa? Qual é a mais fraca?”; 5. “[a]gora marque as afirmações que são corretas, de acordo com o diagrama”; 6."Qual é o propósito deste texto?". A primeira atividade da seção 4, - "[s]obre o que é o diagrama" - e a segunda - “[o] que ele (o diagrama) mostra” - indicam a metafunção representacional do texto, buscando identificar o assunto do texto e questionando sobre os Participantes (inteligências múltiplas, inteligência interpessoal, inteligência lógica, etc, quantidades) e Processos (compara, identifica, descreve).

A identificação das cores no diagrama é muito importante, dessa forma, há referência a elas na atividade: “[o] que as cores e números indicam?”. Essa atividade demanda uma "leitura periférica/superficial" (skimming) (MOTTA-ROTH, 2008, p. 254), requerendo apenas a identificação das cores e números no diagrama. Diferentemente, as atividades “[q]ual é a inteligência mais forte da pessoa? Qual é a mais fraca?" e "[a]gora marque as afirmações que são corretas, de acordo com o diagrama" (p. 56) exigem uma leitura de informações específicas (scanning) (Ibid, p. 257) sobre o 
resultado apresentado no diagrama. Essas três atividades também estão relacionadas à metafunção representacional do diagrama, pois fazem referência aos tipos de inteligência, sua identificação e seus significados.

Nas atividades “[o] que as cores e números indicam?” e "[q]ual é a inteligência mais forte da pessoa? Qual é a mais fraca?" há um destaque para a importância do papel da cor como significado, aplicável também a outros gêneros. Contudo, o porquê de cada cor para cada inteligência ainda poderia ser discutido para se entender como esse item da composição do diagrama influencia a produção de sentido do texto, ou o papel interativo da escolha de uma paleta de cores vibrantes para representar as inteligências. Além disso, outros detalhes composicionais como a razão da disposição de informações nas margens e a circunferência ao centro também poderiam ser discutidos. Na relação margem-centro, "um elemento é posicionado no centro e outros elementos ao seu redor" (KRESS; van LEEUWEN, 2006, p. 196), assim como no diagrama: a circunferência ao centro, quantificando as inteligências que aparecem nas margens.

Outra questão direcionada ao diagrama, "Qual é o propósito deste texto?", visa verificar se os alunos entenderam o objetivo do diagrama, ou seja, que apresenta dados quantitativos de acordo com as respostas a um questionário. De acordo com esse objetivo, o diagrama é uma oferta de informações, que é um dos quatro atos de fala básicos de qualquer texto: oferecer ou demandar informação, oferecer ou demandar serviço (Ibid). A identificação desses atos de fala possibilita uma discussão sobre relações de poder estabelecidos entre leitor e texto e, ainda que esse aspecto não seja explorado explicitamente pela atividade (visto a resposta sugerida), a questão "Qual é o propósito deste texto?" remete primordialmente à metafunção interativa do diagrama.

Assim como na seção 4, nas outras cinco seções também há um destaque à metafunção representacional nas atividades em oposição às outras metafunções. Em vista disso, verificou-se que apesar do caráter multifuncional da linguagem (HALLIDAY; HASAN, 1989), o foco da maior parte das atividades $(84,2 \%)$ está na metafunção representacional, conforme a Tabela 1 . Dessa forma, pode-se dizer que as atividades identificam Participantes, Processos e Circunstâncias nas imagens, enquanto que os papéis dos participantes, suas relações, grau de distanciamento (metafunção interativa) têm papel secundário, e o valor da informação, saliência, molduras (metafunção 
composicional) não são contemplados.

\section{CONSIDERAÇÕES FINAIS}

Kress e van Leeuwen (2006) sinalizam que "educadores em todos os lugares têm estado cientes do crescente papel da comunicação visual em materiais de ensino de vários tipos" (KRESS; van LEEUWEN, 2006, p. 14), no caso da presente pesquisa, o LDI. Nesse sentido, cabe ressaltar aqui as contribuições da Gramática do Design Visual em sala de aula a fim de auxiliar o professor, no sentido de guiar seus alunos a um letramento multimodal, uma vez que apresenta categorias úteis para entender a função/papel dos recursos visuais nos textos (KRESS; van LEEUWEN, 2006).

Contudo, apesar disso, e também de outros autores, como Unsworth (2001) e Cope e Kalantzis (2000), destacarem as crescentes mudanças em termos visuais nos textos, verificou-se um papel secundário das imagens no livro analisado, visto que privilegiam uma das metafunções propostas na Gramática do Design Visual (KRESS; van LEEUWEN, 2006). Segundo Halliday e Hasan (1989) a linguagem é multifuncional, sendo necessário considerar as três metafunções, a fim de uma leitura mais consciente e menos superficial do gênero apresentado.

Para finalizar, vale salientar que este estudo enfoca apenas uma seção do LDI Prime (DIAS; JUCÁ; FARIA, 2010), a seção de leitura, e apenas um volume da coleção. Logo, não é possível apresentar maiores generalizações sobre o livro analisado, sendo relevante para uma pesquisa futura investigar também os outros volumes da mesma coleção, comparar as seções de leitura dos três livros, ou ainda explorar outras seções do mesmo volume.

\section{REFERÊNCIAS}

BRASIL. MEC/SEF. Guia de Livros Didáticos PNLD 2012: Língua Estrangeira Moderna - Ensino Médio. Brasíliạ: FAE, 2011a.

MEC/SEF. Fundo Nacional de Desenvolvimento da Educação: Livro didático - Funcionamento. Brasília: MEC/SEF. Disponível em http://www.fnde.gov.br/index.php/pnld-pnld-e-pnlem. Acesso em: 20 out. 2011 b.

BUNZEN, C. Construção de um objeto de investigação complexo: o livro didático de língua portuguesa. 
Estudos Linguísticos XXXIV, 2005. p. 557-562.

COPE, B.; KALANTZIS, M. Multiliteracies: literacy learning and the design of social futures. London: Routledge, 2000.

DIAS, R.; JUCÁ, L.; FARIA, R. Prime 1: Inglês para o Ensino Médio. Manual do professor. 2a ed. São Paulo: Macmillan, 2010.

GRAY, J. The construction of English. Great Britain: Palgrave Macmillan, 2010.

HALLIDAY M. A K.; HASAN, R. Language, context and text: aspects of language in a social-semiotic perspective. Oxford: Oxford University Press, 1989.

KRESS, G.; VAN LEEUWEN. T. Reading Images: The Grammar of Visual Design. London: Routledge. 1996/2006.

MARTINS, I. Analisando livros didáticos na perspectiva dos Estudos do Discurso: compartilhando reflexões e sugerindo uma agenda para a pesquisa. Pro-Posições, v.17, n. 1 (49). jan./abr. 2006, p. 117-136.

MOTTA-ROTH, D Questões de metodologia em análise de gêneros. In: KARWOSKI, A. M.; GAYDECKA, B.; BRITO, K. S. (Orgs.). Gêneros textuais: Reflexões e ensino.2.ed. Revista aumentada. Rio de Janeiro: Lucerna, 2006. p. 145-163.

. D. Análise crítica de gêneros: contribuições para o ensino e a pesquisa de linguagem. D.E.L.T.A, v.24, n.2, 2008. p. 341-383.

SWALES, J. Genre analysis: English in academic and research settings. Cambridge: Cambridge University Press, 1990/2006.

TICKS, L. K. Contribuições da análise de gênero para o estudo de conceitos de linguagem em livros didáticos e no discurso de professoras de inglês. 2003. 160f. Dissertação (Mestrado em Letras). Universidade Federal de Santa Maria, Santa Maria, 2003.

UNSWORTH, L. Changing dimensions in school literacies. In: UNSWORTH, L. Teaching multiliteracies across the curriculum. Berkshire, QL: Open University Press, 2001. p. 7-20.

\section{A AUTORA}

Daiane Aline Kummer, Especialista, UFSM

E-mail: daianekummer@hotmail.com 